\title{
Employment Income Drops in More Low-Income Than High-Income Households in All States
}

Michael Ettlinger and Jordan Hensley

Low-wage workers are being hit much harder in the COVID-19 economic crisis than higher wage workers. This is evident in the much greater job loss in lower wage industries than higher wage industries. Now new Census Bureau data, collected weekly to monitor the impact of COVID-19 on the economy and society, shows this in another way. Survey respondents were asked the question: "Have you, or has anyone in your household experienced a loss of employment income since March 13, 2020?" The interactive chart shows the answer to this question for the country and every state, by household income level—excluding retirees. Nationally, 60.1 percent of adults living in households with less than $\$ 25,000$ in annual household income had at least one member of their household lose employment income since mid-March. On the other hand, 33.2 percent of adults living in households with income of $\$ 200,000$ or more had a member of their household lose employment income.

Methodology note: Because retirees are less likely to have employment income, and are concentrated in lower household income groups, their inclusion in the Census Bureau tables obscures the impact on the working age population in those income groups. To reduce the impact of retirees on the analysis the authors have used Census Bureau microdata to exclude households where the only adult is a retiree or where a retiree completed the questionnaire and the only other adult is their spouse. Because the microdata are released a week after the tabular data, percentages of retirees are calculated in the past week's microdata and applied to the current week.

An interactive version of the figure can be accessed here.

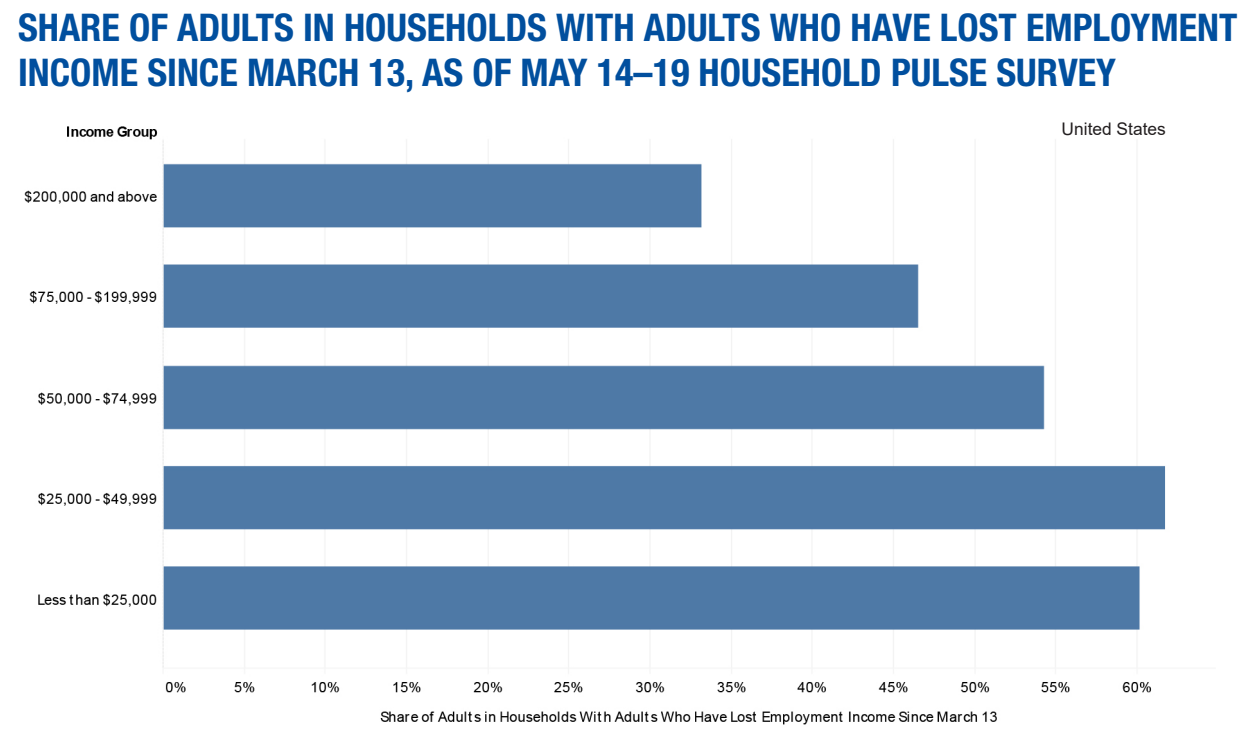

iitii

In states from coast to coast, higher shares of adults in low-income households have lost employment income than adults in higher income households.

\author{
About the Authors \\ Michael Ettlinger is the founding \\ director of the Carsey School of \\ Public Policy. \\ Jordan Hensley is a policy \\ analyst at the Carsey School of \\ Public Policy.
}

See Related Publications at carsey.unh.edu

- COVID-19 Economic Crisis:

By State (May 2020)

- Mapping State Unemployment (April 2020) 